\title{
Management of Itch in the Elderly: A Review
}

Kayla M. Fourzali · Gil Yosipovitch

Received: August 15, 2019 / Published online: September 23, 2019

(C) The Author(s) 2019

\begin{abstract}
Chronic itch is common in the elderly patient and may be caused by a variety of known dermatologic and non-dermatologic conditions and can have a significant effect on quality of life. Age-related changes in barrier function, immunosenescence, and neuronal changes and neuropathies are common predisposing factors to chronic itch in this age group. Certain primary dermatologic conditions are more common in the elderly and can cause chronic itch. Also, co-morbid diseases particularly of the renal, hepatobiliary, or hematologic systems, psychologic conditions, or medications may contribute to chronic itch in this population. Thus, medical workup for an elderly patient with chronic itch requires special attention to the patient's medical history, current health status, and medications. Topical treatments and emollients may be recommended for elderly patients, with consideration of specific adverse effects and alternatives. Systemic medications pose a higher risk of adverse effects and many
\end{abstract}

Enhanced Digital Features To view enhanced digital features for this article go to https://doi.org/10.6084/ m9.figshare.9767126.

K. M. Fourzali · G. Yosipovitch ( $₫)$

Dr. Phillip Frost Department of Dermatology and

Cutaneous Surgery and Miami Itch Center,

University of Miami, Miami 33136, USA

e-mail: gyosipovitch@med.miami.edu are contraindicated in the elderly for this reason. In addition, management in the elderly may be complicated by differential pharmacokinetics of medications, the presence of comorbid health conditions, cognitive disorders, physical limitations, and polypharmacy. New and emerging treatment modalities hold promise for use in the elderly due to these special considerations.

Keywords: Elderly; Geriatric; Itch; Management; Pruritus

\section{INTRODUCTION}

Diseases that cause itch are some of the most common dermatologic complaints in the elderly (age 65 and above) with prevalence estimates up to $37.5 \%$ [1-3]. Chronic itch, defined as present for more than 6 weeks, can be debilitating and significantly affect quality of life [4-7]. Primary dermatologic conditions account for up to $28 \%$ of the chronic itch seen in some elderly populations [8]. In addition, the elderly are more likely to have itch due to agerelated changes in the skin, co-morbid systemic disease, medication effects, and psychological conditions [9]. Medical workup for an elderly patient with chronic itch requires special attention to the patient's history of disease, consideration of undiagnosed systemic disease, 
co-morbid psychologic conditions, as well as comprehensive review of the patient's current topical and systemic therapies. The clinical presentation of itch may vary widely depending on the underlying etiology. Primary dermatologic conditions will most often have a recognizable skin manifestation ranging from a localized rash to erythroderma, while neuropathic, systemic, or psychogenic etiologies may present with no rash or only secondary skin lesions. Despite a thorough medical review and workup, chronic itch has no identifiable cause in up to $11 \%$ of cases [10]. Chronic pruritus of unknown origin is common in the elderly and most cases likely represent the same unknown etiology as the general population [11]. In the elderly, management of chronic itch may be complicated by a variety of issues, including differential effects of medications in the elderly, co-morbid health conditions, cognitive disorders, physical limitations, and polypharmacy. This article aims to provide an updated review of causes of chronic itch in the elderly and management strategies in this population. This article is based on previously conducted studies and does not contain any studies with human participants or animals performed by any of the authors.

\section{AGE-RELATED CHANGES IN THE SKIN}

The most common cause of chronic itch in the elderly is xerosis related to aging, seen in over $50 \%$ of the elderly [12]. The underlying mechanism is thought to be due to loss of integrity of barrier function provided by the stratum corneum and subsequent inability to maintain epidermal water content. With age, alkalization of the skin leads to dysfunction of enzymes required for basic repair functions and production of lipids that are necessary for maintenance of the water barrier. Alkalization has also been shown to lead to increased activity of serine proteases and activation of protease-activated receptors (PARs) that induce non-histaminergic chronic itch [13, 14]. Aging skin has been shown to have reduced levels of ceramide-generating enzymes within the stratum corneum
[15]. Also, aged skin shows reduced sebum production and in female patients this occurs with the onset of menopause, implying a role of estrogen reduction [16]. Expression of aquaporins that are integral in the maintenance of epidermal water content has been shown to be reduced in aging skin [17]. Xerosis typically presents as itch with dry, cracked, flaking skin often on the extremities and trunk. The scratching response leads to further disruption of the barrier contributing to risk for superimposed infection and continuation of the itchscratch cycle can lead to further inflammation and worsening of chronic itch.

Immune function is expected to decline with age, with decreases in the response of the innate and adaptive immune systems. There is a reduction of naïve $\mathrm{T}$ cells, favoring memory cells as well as a shift toward $\mathrm{CD}^{+}$predominance over $\mathrm{CD}^{+}$and a predominance of the Th2-type response over the Th1-type response, with corresponding inflammatory cytokines [18-20]. B cell populations are also reduced in number accompanied by imbalance of immunoglobulin production [21]. These and other adaptive immunologic changes lead to a diminished response against novel pathogens, malignancy, and vaccinations seen in the elderly [22]. Reduced barrier function contributes to increased susceptibility to pathogens as well as release of proinflammatory cytokines such as interleukin-6 (IL-6) and tumor necrosis factor alpha, predisposing to inflammatory skin conditions $[20,23]$. In addition, morphologic changes and reduction in number of Langerhans cells have been demonstrated in aging and photodamaged skin [24, 25].

Finally, degenerative diseases that more commonly affect the elderly may cause central or peripheral nerve damage leading to neuropathy and neuropathic itch (NI). NI can present a diagnostic challenge, since secondary excoriations may mimic a primary dermatologic condition. Characteristic features include absence of primary dermatologic lesions, nonresponsiveness to antihistamine, relief from application of cold compress, and is more likely to be accompanied by depressed mood, sleep disturbance, and reduction in quality of life [7]. Also, NI tends to be rated by the patient as 
severe in quality [10]. Another hypothesis to explain NI is evidence of reduced epidermal nerve fiber density in the elderly, potentially leading to reduced density of nerves that inhibit the itch sensation [26]. Intraepidermal nerve fiber density has been shown to be reduced in those with chronic itch, with increased sensitivity to pruritic stimulation [27].

\section{Dermatologic Conditions Causing Itch in the Elderly}

\section{Seborrheic Dermatitis}

Common in the elderly, seborrheic dermatitis is associated with Malassezia yeast species in the setting of reduced immune function. This disease in the elderly has also been shown to have an association with Parkinson disease and psychiatric conditions such as depression and anxiety [28, 29].

\section{Stasis Dermatitis}

Chronic venous insufficiency leading to stasis dermatitis is a pruritic disease seen in increased prevalence in the elderly $[2,8]$. The common manifestations of edema, brownish plaque with scale, petechiae, and pruritus are most typically seen in the lower leg above the medial malleolus.

\section{Nummular Eczema}

Considered a variant of atopic dermatitis (AD), nummular eczema can present as an acute or chronic pruritic eruption in the elderly even in the absence of prior atopic disease $[2,30]$. Agerelated xerosis is likely a predisposing factor [31].

\section{Contact Dermatitis}

Whether of the allergic or irritant form, contact dermatitis is common in the elderly occurring in up to $13 \%$ [8]. Reductions in epidermal barrier and immune function are likely predisposing factors in the elderly but may also contribute to a more subtle inflammatory response [32].

\section{Prurigo Nodularis (PN)}

$\mathrm{PN}$ is a condition commonly seen in elderly individuals in the setting of chronic itch and scratching caused by any number of primary dermatologic, neuropathic, and systemic diseases such as end-stage renal disease (ESRD) and human immunodeficiency virus. PN nodules and lichenified lesions are usually distributed in "reachable" areas on the extremities, upper back, and buttocks. PN-related itch may disrupt sleep, affect quality of life, and is associated with psychiatric co-morbidities [33].

\section{Psoriasis}

Itch associated with psoriasis is a commonly encountered symptom in the elderly $[8,34]$. In the elderly, psoriasis typically presents as chronic plaque-type similar to the general population; however, later onset psoriasis may present with a less severe presentation [35].

\section{Bullous Pemphigoid (BP)}

$\mathrm{BP}$ is most often seen in the elderly and known triggers include viral infections and certain medications but the majority of cases have no apparent trigger [36]. BP is also associated with Parkinson disease and dementia [37]. Itch in BP has been recently correlated to several mediators including substance P and IL-31 and activation of eosinophils and basophils [38]. BP may initially present with a prodrome of nonbullous, non-specific eczematous skin changes accompanied by pruritus lasting months to years prior to the presentation of tense bullae [39].

\section{Scabies}

Scabies is commonly diagnosed at the extremes of ages with outbreaks notable among those living in care facilities or nursing homes [40]. Itch caused by scabies is thought to be mediated by non-histaminergic pathways involving tryptase and its corresponding receptor proteaseactivated receptor 2 (PAR2) as well as transient receptor potential vanilloid receptor 1 and transient receptor A1 (TRPV1 and TRPA1) [41]. Scabies presents as an intensely pruritic rash typically with excoriations evident. Pruritus is often most intense during the nighttime hours 
or after hot showers. Scratch-induced skin damage may lead to secondary infection with staphylococcal or streptococcus species, particularly in those with suppressed immune conditions or co-morbid disease states. The mite has a predilection for the acral sites but whole body involvement is a common feature of disease in the elderly or immunocompromised.

\section{Neuropathic Itch}

\section{Diabetes Mellitus (DM)-Related Polyneuropathy}

Itch is reported in up to $26.3 \%$ of individuals with DM [42]. Pruritus is more likely to occur in individuals with typical symptoms of lower extremity polyneuropathy but may also present as generalized itch or localized to areas other than the lower extremities such as the scalp, trunk, or genitals [43].

\section{Post Herpetic Itch}

Post herpetic neuralgia (PHN) is a sensory syndrome secondary to herpes zoster reactivation (shingles), which most commonly affects the elderly because of age-related reduction in immunologic suppression of the virus. Viral reactivation may damage sensory afferents in the affected dermatome, causing pain, itch, and paresthesia that may last months or years following the resolution of skin lesions. The likelihood of an individual suffering from PHN increases with the age at which they are affected, with an incidence of $10 \%$ in those affected at ages $60-69$ and up to $20 \%$ in those over age 80 [44].

\section{Radiculopathy}

Nerve compression due to spinal osteoarthritis, infection, trauma, or tumors may lead to NI. Notalgia paresthetica (NP) and brachioradial pruritus (BRP) are two well-described nerve compression syndromes causing itch in the elderly, more commonly in women. NP is often related to osteoarthritic degeneration and impingement of thoracic nerve roots leading to pruritus accompanied by burning or pain in the upper back. Often, secondary skin changes are notable as a hyperpigmented patch. BRP is related to compression pathologies in the C3-C7 region $[45,46]$. The itch, stinging, and burning of BRP is often bilateral and typically localized to the dorsolateral forearms and arms, at times extending to the shoulders and in some cases progressing to generalized pruritus involving the lower extremities and trunk [47].

\section{Systemic or Organ-Specific Disease}

Diseases of the hepatobiliary, hematologic, and renal systems are well-known causes of chronic itch. As a result of the increased prevalence of such diseases in the elderly, comprehensive workup of all major organ systems including complete blood count, erythrocyte sedimentation rate as well as renal, hepatobiliary, and thyroid function studies is necessary, particularly in the absence of evidence of a primary dermatologic or neurogenic etiology. Determining the cause of itch related to a systemic disorder is crucial, as it may be the presenting symptom of a progressive disease for which treatment is indicated.

\section{ESRD-Related Itch (Uremic Itch)}

ESRD-related itch is reported in up to $66 \%$ of those undergoing hemodialysis and typically involves the torso and is symmetrical in the extremities [48, 49]. The cause of itch in those with ESRD is not fully understood but the mechanism has been proposed to be due to several factors including lowered threshold for itch, hyperparathyroidism, and imbalance of endogenous opioids [50].

\section{Cholestatic Itch}

The primary feature of hepatobiliary cholestatic itch is itch on the palms and soles [50,51]. The pathophysiology of cholestatic itch has not been wholly elucidated, but serum levels of lysophosphatidic acid and autotaxin, endogenous opioids, histamine, and bile acids have been shown to be elevated in those affected with cholestatic itch, alluding to their involvement in itch pathogenesis or at least correlation with causative factors [52]. 


\section{Myeloproliferative Disorders and Malignancy}

Polycythemia vera (PV), essential thrombocytosis, and primary myelofibrosis are known to have aquagenic itch as a predominant symptom and it is the presenting symptom in up to $36 \%$ of cases of PV [53, 54]. The relationship is thought to be related to proliferation of mast cells and/or basophils [55]. Pruritus is a welldescribed symptom associated with hematologic malignancies, reported in up to $30 \%$ of patients with Hodgkin lymphoma and multiple myeloma, and less frequently in non-Hodgkin lymphoma and leukemia [56, 57]. Generalized itch with or without eczematous lesions precedes the diagnosis of Hodgkin lymphoma in some cases [58]. Malignancies originating in the skin itself may also present with itch. Cutaneous $\mathrm{T}$ cell lymphoma (CTCL) commonly manifests as itch and itch severity has been found to correlate with severity of disease [59]. Non-melanoma skin cancers, basal cell and squamous cell, present as localized itch in 33\% and $43 \%$ of cases, respectively [60]. Internal malignancies such as pancreatic or biliary tumors may lead to cholestatic itch [61]. Itch may present as a paraneoplastic sign of hematologic malignancies or solid tumors without associated dermatologic lesions or along with acanthosis nigricans, dermatomyositis, transient acantholytic dermatosis (Grover's disease), or eruptive seborrheic keratosis (Leser-Trélat sign) [57].

\section{Psychogenic Itch}

Psychiatric disorders are common in the elderly but may be under-recognized or under-reported as a result of cognitive co-morbidities in this population [62]. Psychogenic itch refers to an intense urge to scratch or pick at the skin, without known primary dermatologic or systemic etiology. Thus, psychogenic itch is often a diagnosis of exclusion and it is not recognized in the current Diagnostic and Statistical Manual of Mental Disorders (DSM-V). Psychogenic itch most commonly presents in individuals with psychiatric conditions and has been associated with obsessive compulsive disorder, somatic symptom disorder, excoriation disorder, fibromyalgia, and delusional infestation [63]. Psychogenic itch has also been reported as a symptom of neurodegenerative disorders such as dementia and as an effect of medications activating dopaminergic pathways $[64,65]$.

\section{Medication-Induced Itch}

A number of medications commonly prescribed in the elderly induce itch as a known adverse effect, most commonly opioid pain medications, antihypertensives (angiotensin-converting enzyme inhibitors, calcium channel blockers), antibiotics (penicillin derivatives), and antidepressants (tricyclic antidepressants, TCAs) $[66,67]$. Pruritus is reported in $2-10 \%$ of patients treated with oral systemic opioids, but that percentage increases dramatically with epidural or intrathecal administration [68]. Opioid-induced itch is thought to be due to activation of centrally located mu-opioid receptors as well as peripheral mast cell activation and subsequent histamine action [68]. The new anticancer checkpoint inhibitors, specifically ipilimumab (targeting cytotoxic $\mathrm{T}$ lymphocyte associated antigen 4, CTLA4) and pembrolizumab (targeting programmed cell death protein 1, PD-1) for use in the treatment of melanoma have been shown to induce pruritus with and without rash [69]. Targeted inhibitors of epidermal growth factor receptor (EGFR), indicated for use in metastatic colon cancer, head and neck cancer, and lung cancer, as well as BRAF inhibitors used for metastatic melanoma have notable dermatologic side effects including pruritus in up to $31 \%$ and $18 \%$ of patients, respectively [70].

\section{TOPICAL TREATMENTS AND CONSIDERATIONS IN THE ELDERLY}

Treatment of xerosis is targeted at improving the barrier function of the skin and limiting epidermal water loss. Initial treatment measures may be non-pharmacologic in nature, including alterations to the bathing regimen (mild low $\mathrm{pH}$ cleansers, lukewarm water), frequent moisturization with ointments or cream on damp skin, and avoidance of irritants (Table 1). Daily oatmeal baths are another treatment option as 
Table 1 Treatment of itch by type in the elderly

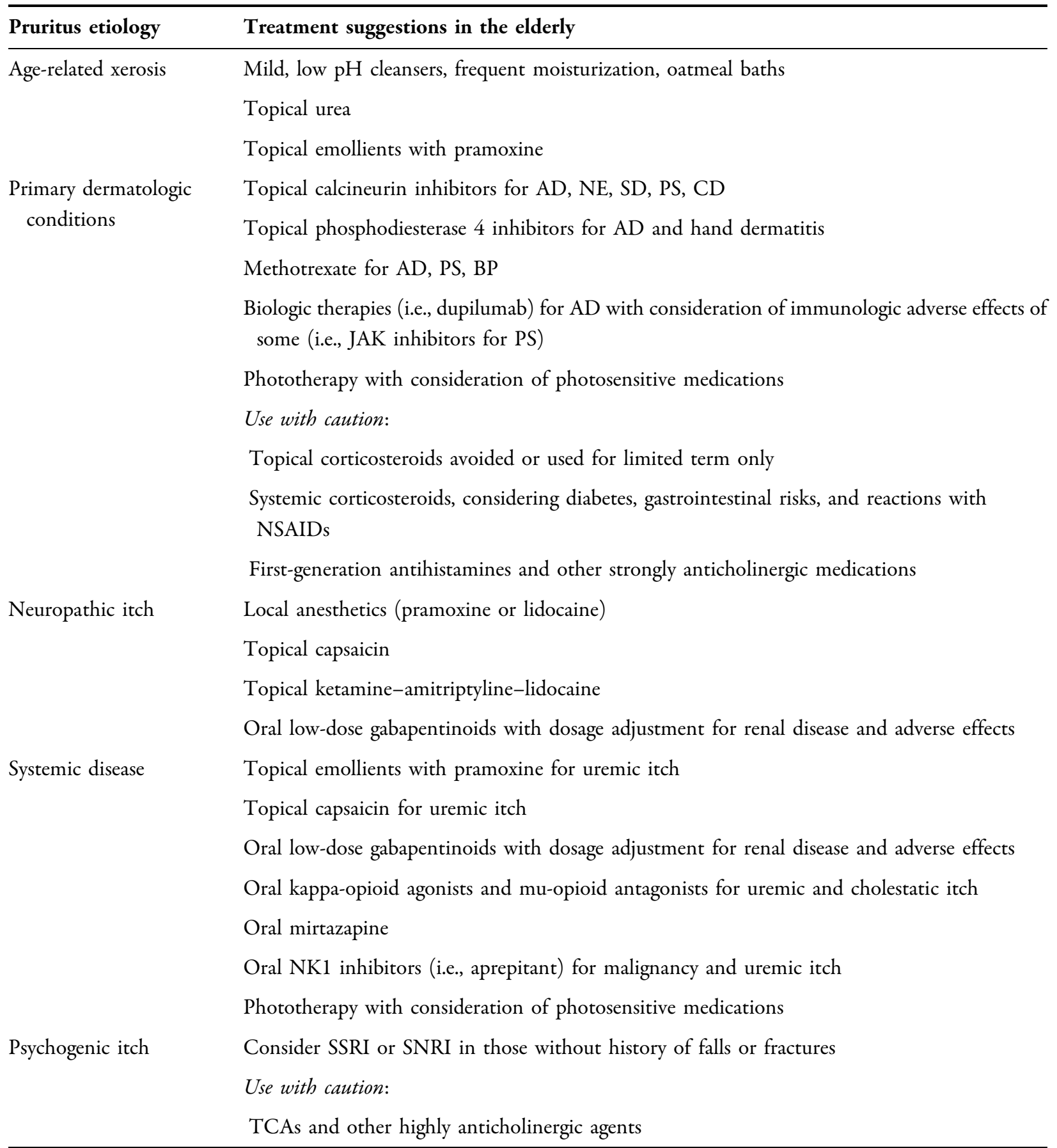

$A D$ atopic dermatitis, $N E$ nummular eczema, $S D$ seborrheic dermatitis, $P S$ psoriasis, $C D$ contact dermatitis, $B P$ bullous pemphigoid, $J A K$ janus kinase, NSAID non-steroidal anti-inflammatory, NKI neurokinin 1, SSRI selective serotonin reuptake inhibitor, $S N R I$ serotonin and norepinephrine reuptake inhibitor, TCA tricyclic antidepressants

moisturization with colloid oatmeal-based products has been shown to improve appearance of lesions and reducing pruritus in patients with xerosis and other skin conditions 
$[71,72]$. Topical urea, a moisturizing keratolytic agent, is an effective treatment for several causes of itch including xerosis, with minimal side effects [73]. In addition, a local anesthetic such as pramoxine added to emollients has been shown effective in treatment of ESRD-related itch [74].

Treatment of NI is often challenging, as it is typically resistant to antihistamines and topical corticosteroids [75]. An effective topical treatment is capsaicin $0.025-0.075 \%$, which acts through activating the TRPV1 receptors in the skin to desensitize local nerves [76]. A significantly higher capsaicin concentration of $8 \%$ in patch form has shown to be effective in treatment of NI [77-79]. However, the high cost of this drug has prevented its use in the USA. The effect of capsaicin is induction of localized pain and burning sensation that can be reduced by application of local anesthetic cream. Another topical treatment that has demonstrated effectiveness in NI is a combination of ketamine-amitriptyline-lidocaine [80, 81]. The mechanism of this topical is through blockade of the $\mathrm{N}$-methyl-D-aspartate receptor and sodium channels, which is proposed to reduce sensitivity of local peripheral nerves [80].

Topical corticosteroids are among the firstline treatments for common itch pathologies in which there is an inflammatory component such as $\mathrm{AD}$, psoriasis, seborrheic dermatitis, or contact dermatitis [82, 83]. Long-term use of topical corticosteroids can cause thinning, atrophic effects, and disruption of skin barrier function, which may exacerbate atrophic changes already present in aging skin [84]. Therefore, long-term use of topical corticosteroids should be avoided if possible. Other topical agents such as calcineurin inhibitors do not have known atrophic effects on the skin and may be a reasonable alternative for treatment of these inflammatory conditions $[85,86]$. Another alternative with minimal adverse effects is crisaborole, a phosphodiesterase 4 inhibitor that reduces pro-inflammatory cytokines and has shown effectiveness in itch in moderate to severe AD [87].

\section{SYSTEMIC MEDICATIONS AND PRECAUTIONS IN THE ELDERLY}

Oral and systemic medications are commonly used in geriatric itch, but require cautionary use (see Tables 1,2). Adverse effects of medications are generally more common in the elderly. Polypharmacy potentiates the risk for drug-drug interactions, as there are many medications commonly used in the elderly that have specific interactions with the hepatic cytochrome p450 (CYP) metabolism pathways. Substrates of CYP enzymes likely to be affected by these metabolic effects include several commonly used medications, highlighting the necessary review of all medications, dermatologic and otherwise, prior to initiating treatment $[88,89]$.

In addition to drug-drug interactions, adverse effects should be considered carefully in the elderly. Medication adverse effects such as sedation, vertigo, or fatigue that may be mild or tolerated in the younger population may exacerbate already existing limitations in mobility and cognitive function. Careful review of medication side effects is necessary as well as considerations for initiating dosages at reduced levels, particularly with medications that have a narrow therapeutic window [88].

Physiologic changes with age also contribute to the effective distribution and elimination of medications. Muscle mass is generally decreased in the elderly while body fat is increased, leading to potential prolongation of effects or severity of lipid soluble medications [90]. A large percentage of the elderly population has reduced kidney function. Dermatologic medications used for itch-related diseases that undergo renal clearance and thus require consideration of renal dosing include cetirizine and gabapentin, among others [88].

\section{First-Generation Antihistamines}

These drugs have been commonly used to relieve itch for decades, despite little supportive data for their effectiveness in non-histaminergic etiologies. The American Geriatric Society (AGS) Beers Criteria have made a strong 
Table 2 Topical and systemic therapies for itch in the elderly

\begin{tabular}{ll}
\hline Topical therapies for itch in the elderly & Systemic therapies for itch in the elderly \\
\hline $\begin{array}{l}\text { Benefits } \\
\begin{array}{l}\text { Limited systemic effects and therefore fewer interactions and } \\
\text { potential for toxic effects }\end{array}\end{array}$ & $\begin{array}{l}\text { Systemic effect for treatment of extensive pruritus } \\
\text { Application as needed to target areas }\end{array}$ \\
$\begin{array}{l}\text { May target receptor, cytokine, or immune process specific } \\
\text { to underlying disease }\end{array}$ \\
$\begin{array}{l}\text { Burdensome to use in extensive skin disease, may require large } \\
\text { volume }\end{array}$ & $\begin{array}{c}\text { Potential for systemic adverse effects and medication } \\
\text { interactions }\end{array}$ \\
Requires patient education of application technique & $\begin{array}{c}\text { May require dosage adjustments for systemic disease } \\
\text { states }\end{array}$ \\
Topical corticosteroids may lead to atrophic changes in elderly &
\end{tabular}

recommendation against their use in the elderly as a result of their highly anticholinergic properties and risk for delirium $[88,91]$. In addition, recent evidence from a large prospective cohort study of elderly patients shows that use of medications with strong anticholinergic effects (i.e., first-generation antihistamines or TCAs) may contribute significantly to risk for Alzheimer disease [92]. Second-generation antihistamines are preferred for treatment of histaminergic forms of itch such as chronic urticaria owing to their reduced anticholinergic effects [93]. Loratadine, however, has the most anticholinergic effects of all the second-generation antihistamines, and should be avoided in the elderly [88].

\section{Antidepressants}

TCAs such as amitriptyline and doxepin are also recommended against because of their anticholinergic effects as well as orthostatic hypotension [91]. TCAs have been shown to be effective in the treatment of nocturnal itch and psychogenic itch [75]. Alternatives for the treatment include antidepressants with a more favorable side effect profile in the elderly, such as the selective serotonin reuptake inhibitors (SSRIs) and serotonin and norepinephrine reuptake inhibitors (SNRIs) as well as behavioral therapy or psychotherapy [75]. The SSRIs paroxetine, fluvoxamine, and sertraline have been shown to have antipruritic effects in AD, lymphoma, and cholestatic pruritus [94-96]. However, the SSRIs and SNRIs are not without their potential adverse effects in the elderly, as both classes were recently added to the AGS Beers Criteria to be avoided in those with a history of falls or fractures, as a result of evidence increased risk of hip fractures [97]. In addition, paroxetine has the greatest anticholinergic properties of that class of medications and therefore would not be the SSRI of choice for treatment in an elderly patient [91]. Mirtazapine, an antidepressant that blocks adrenergic alpha 2 receptors and $5-\mathrm{HT}_{2}$ receptors has shown effectiveness at low doses in relieving nocturnal itch. This medication in low doses of 7.5-15 mg may be preferred for select patients owing to its effects on somnolence and increased appetite [98].

\section{Systemic Corticosteroids and Immunosuppressants}

Corticosteroids are used frequently in inflammatory and immune-mediated dermatologic conditions that cause itch. The known adverse effects of systemic include hypertension, hyperglycemia, osteoporosis, and myopathy. In 
addition, caution must be taken to avoid the use of corticosteroids in combination with the nonsteroidal anti-inflammatories (NSAIDs) in the elderly, as this increases the risk of peptic ulcers and gastrointestinal bleeding [91]. Other pan-T cell immunosuppressants such as cyclosporine, which has many side effects as high blood pressure, renal damage, and systemic infections, should be avoided. Low-dose methotrexate is a safer alternative that can be effective for itch caused by AD, psoriasis, BP, and urticaria [99].

\section{Anti-Epileptics}

Gabapentinoids such as gabapentin and pregabalin show efficacy in treating NI due to PHN, $\mathrm{BRP}$, and NP, or spinal cord injury as well as uremic itch [42, 100-102]. Because of renal clearance, dose adjustments may be required in the elderly or those with kidney disease. Potential adverse effects such as sedation and ataxia are of concern in elderly patients with limited baseline mobility or cognitive functioning [101]. To moderate these unwanted effects, it is recommended that dosage of gabapentin in the elderly be initiated at $100-300 \mathrm{mg}$ (pregabalin 25-75 mg) at night and slowly titrated up [88].

\section{Opioid System Targets}

Opioids are a well-described cause of medication-induced pruritus and do so through activation of central mu-opioid receptors [103]. Medications that antagonize the mu-opioid receptor, such as naloxone, naltrexone, or nalmefene, have been demonstrated to be effective in reducing itch in chronic urticaria, $\mathrm{AD}, \mathrm{PN}$ as well as cholestatic and uremic itch [104]. Side effects including nausea, vomiting, diarrhea, dizziness, and fatigue and the potential for hepatic injury at high doses necessitate caution with the use in the elderly [105]. In contrast, activation of kappa-opioid receptors inhibits pruritus. Butorphanol, a kappa-opioid agonist with some mu-opioid antagonist properties, has been shown in case series to effectively reduce itch due to $\mathrm{PN}$, cholestasis, uremic itch, and idiopathic pruritus in elderly patients
$[104,106]$. Nalfurafine, which has a similar mechanism of action, has been demonstrated in randomized controlled trials (RCTs) to reduce uremic itch and cholestatic itch and is currently only used clinically in Japan [107]. Side effects have been noted to be minimal with insomnia most commonly reported followed by constipation and somnolence [107]. New kappa-opioid agonists in the pipeline such as nalbuphine and CR845 show promise in early phase trials for uremic itch with a favorable safety profile [106, 108, 109].

\section{Biologic Therapies}

Dupilumab, a monoclonal antibody targeting the receptor for IL-4, has been shown in large RCTs to reduce symptoms and improve quality of life in those with moderate to severe $A D$ $[110,111]$. The average age of participants in these trials was under 50, providing little evidence of efficacy in the elder population. We have gained clinical experience using this drug in older patients with success, including a 95-year-old with itch refractory to other treatments (Yosipovitch, unpublished data). Adverse effects have not been specifically outlined in the elderly, but in the general adult population they include conjunctivitis, headache, and injection site reaction. There has been no demonstrated increased risk of secondary infections such as herpes viral infections or urinary tract infections that would be of particular concern when prescribing to the elder patient [112]. Several additional biologic therapies including targets of IL-31 and JAK show promise in early phase trials for their antipruritic properties particularly for $\mathrm{AD}, \mathrm{PN}$, and chronic idiopathic pruritus $[113,114]$. JAK inhibitors such as tofacitinib have adverse effects that should be strongly considered when used in the elderly including increased risk of herpes and other infections [115].

\section{Neurokinin (NK1) Antagonists}

NK1 is the receptor for substance P, and antagonist medications such as aprepitant and serlopitant have been shown to be effective in 
reducing itch of various etiologies, including malignancy, ESRD, idiopathic itch, and PN $[115,116]$. The relatively mild adverse effect profile of aprepitant has been demonstrated in several RCTs for use in other disease states such as depression and chemotherapy-induced nausea [117]. However, aprepitant is a known inducer of CYP3A4 and therefore has the potential for many drug-drug interactions [117].

\section{Phototherapy}

Ultraviolet A and B (UV-A and UV-B) phototherapy has been shown to improve pruritus in patients with $\mathrm{AD}$, psoriasis, ESRD, and CTCL with limited evidence of its utility in PN [118-120]. In one retrospective study, Bulur et al. demonstrated elimination of pruritus in $80 \%$ of their elderly patients receiving narrowband UV-B treatment for chronic idiopathic pruritus [121]. Known risks of phototherapy include an erythematous sunburn reaction, aging of the skin, increased risk for non-melanoma skin cancer, and a paradoxical induction of itch if phototherapy doses are too high [122]. Despite concerns of potential adverse effects due to age-related barrier and immune function, the minimal dose to cause erythema has not been shown to differ significantly between older and younger populations and adverse effects are reported at comparable rates $[123,124]$. However, at least one study found that if erythema was elicited by phototherapy, the intensity was significantly increased in the elderly [124]. Consideration for low doses should be made for patients with high cumulative sun exposure or history of skin cancer. Also of note, some frequently used medications (i.e., antibiotics, NSAIDs, antihypertensives, and diuretics) can cause photosensitivity, and should not be used in conjunction with phototherapy.

\section{CONCLUSIONS}

Chronic itch is a common symptom in the elderly population and may be due to age-related changes in the skin, primary dermatologic conditions, systemic disease, neuropathic diseases, or medications. Determining the underlying cause of chronic itch is necessary for appropriate treatment. Because of medical comorbidities, differential pharmacokinetics, polypharmacy, and potential for adverse reactions in the elderly, caution must be taken with certain medical therapies for chronic itch in this population.

\section{ACKNOWLEDGEMENTS}

Funding. No funding or sponsorship was received for this study or publication of this article.

Authorship. All named authors meet the International Committee of Medical Journal Editors (ICMJE) criteria for authorship for this article, take responsibility for the integrity of the work as a whole, and have given their approval for this version to be published.

Disclosures. Gil Yosipovitch is Scientific Board Member of Menlo, Trevi, Sienna, Sanofi, Regeneron, Galderma, Pfizer, Novartis, Bayer, Kiniksa, Eli Lilly, Abbvie, Ortho, and Cervae and has received research support from Pfizer, Sun Pharma, Leo, Menlo, and Kiniksa. Kayla M. Fourzali has nothing to disclose.

Compliance with Ethics Guidelines. This article is based on previously conducted studies and does not contain any studies with human participants or animals performed by any of the authors.

Open Access. This article is distributed under the terms of the Creative Commons Attribution-NonCommercial 4.0 International License (http://creativecommons.org/licenses/ by-nc/4.0/), which permits any noncommercial use, distribution, and reproduction in any medium, provided you give appropriate credit to the original author(s) and the source, provide a link to the Creative Commons license, and indicate if changes were made. 


\section{REFERENCES}

1. Thapa DP, Jha AK, Kharel C, Shrestha S. Dermatological problems in geriatric patients: a hospital based study. Nepal Med Coll J. 2012;14(3):193-5.

2. Yalcin B, Tamer E, Toy GG, Oztas P, Hayran M, Alli $\mathrm{N}$. The prevalence of skin diseases in the elderly: analysis of 4099 geriatric patients. Int J Dermatol. 2006;45(6):672-6.

3. Weisshaar E, Szepietowski JC, Dalgard FJ, et al. European S2k guideline on chronic pruritus. Acta Derm Venereol. 2019;99(5):469-506.

4. O'Donnell BF, Lawlor F, Simpson J, Morgan M, Greaves MW. The impact of chronic urticaria on the quality of life. Br J Dermatol. 1997;136(2):197-201.

5. Yosipovitch G, Goon A, Wee J, Chan YH, Goh CL. The prevalence and clinical characteristics of pruritus among patients with extensive psoriasis. Br J Dermatol. 2000;143(5):969-73.

6. Yosipovitch G, Zucker I, Boner G, Gafter U, Shapira Y, David M. A questionnaire for the assessment of pruritus: validation in uremic patients. Acta Derm Venereol. 2001;81(2):108-11.

7. Kini SP, DeLong LK, Veledar E, McKenzie-Brown AM, Schaufele M, Chen SC. The impact of pruritus on quality of life: the skin equivalent of pain. Arch Dermatol. 2011;147(10):1153-6.

8. Valdes-Rodriguez R, Mollanazar NK, Gonzalez-Muro $\mathrm{J}$, et al. Itch prevalence and characteristics in a Hispanic geriatric population: a comprehensive study using a standardized itch questionnaire. Acta Derm Venereol. 2015;95(4):417-21.

9. Berger TG, Shive M, Harper GM. Pruritus in the older patient: a clinical review. JAMA. 2013;310(22):2443-50.

10. Mollanazar NK, Sethi M, Rodriguez RV, et al. Retrospective analysis of data from an itch center: integrating validated tools in the electronic health record. J Am Acad Dermatol. 2016;75(4):842-4.

11. Kim BS, Berger TG, Yosipovitch G. Chronic pruritus of unknown origin (CPUO): uniform nomenclature and diagnosis as a pathway to standardized understanding and treatment. J Am Acad Dermatol. 2019. https://doi.org/10.1016/j.jaad.2019.06.038.

12. Paul C, Maumus-Robert S, Mazereeuw-Hautier J, Guyen CN, Saudez X, Schmitt AM. Prevalence and risk factors for xerosis in the elderly: a cross-sectional epidemiological study in primary care. Dermatology. 2011;223(3):260-5.
13. Ali SM, Yosipovitch G. Skin pH: from basic science to basic skin care. Acta Derm Venereol. 2013;93(3):261-7.

14. Akiyama T, Lerner EA, Carstens E. Protease-activated receptors and itch. Handb Exp Pharmacol. 2015;226:219-35.

15. Jensen JM, Forl M, Winoto-Morbach S, et al. Acid and neutral sphingomyelinase, ceramide synthase, and acid ceramidase activities in cutaneous aging. Exp Dermatol. 2005;14(8):609-18.

16. Luebberding S, Krueger N, Kerscher M. Age-related changes in skin barrier function - quantitative evaluation of 150 female subjects. Int J Cosmet Sci. 2013;35(2):183-90.

17. Li J, Tang H, Hu X, Chen M, Xie H. Aquaporin-3 gene and protein expression in sun-protected human skin decreases with skin ageing. Australas J Dermatol. 2010;51(2):106-12.

18. Ventura MT, Casciaro M, Gangemi S, Buquicchio R. Immunosenescence in aging: between immune cells depletion and cytokines up-regulation. Clin Mol Allergy. 2017;15:21.

19. Di Lorenzo G, Di Bona D, Belluzzo F, Macchia L. Immunological and non-immunological mechanisms of allergic diseases in the elderly: biological and clinical characteristics. Immun Ageing. 2017;14:23.

20. Lang P, Mitchell W, Lapenna A, Pitts D, Aspinall R. Immunological pathogenesis of main age-related diseases and frailty: role of immunosenescence. Eur Geriatr Med. 2010;1(2):112-21.

21. Colonna-Romano G, Bulati M, Aquino A, et al. B cell immunosenescence in the elderly and in centenarians. Rejuvenation Res. 2008;11(2):433-9.

22. Haynes L, Maue AC. Effects of aging on T cell function. Curr Opin Immunol. 2009;21(4):414-7.

23. Berger TG, Steinhoff M. Pruritus in elderly patients-eruptions of senescence. Semin Cutan Med Surg. 2011;30(2):113-7.

24. Grewe M. Chronological ageing and photoageing of dendritic cells. Clin Exp Dermatol. 2001;26(7):608-12.

25. Zegarska B, Pietkun K, Giemza-Kucharska P, Zegarski T, Nowacki MS, Romanska-Gocka K. Changes of Langerhans cells during skin ageing. Postepy Dermatol Alergol. 2017;34(3):260-7.

26. Goransson LG, Mellgren SI, Lindal S, Omdal R. The effect of age and gender on epidermal nerve fiber density. Neurology. 2004;62(5):774-7. 
27. Pogatzki-Zahn EM, Pereira MP, Cremer A, et al. Peripheral sensitization and loss of descending inhibition is a hallmark of chronic pruritus. J Invest Dermatol. 2019. https://doi.org/10.1016/j.jid.2019. 05.029 .

28. Comert A, Akbas B, Kilic EZ, et al. Psychiatric comorbidities and alexithymia in patients with seborrheic dermatitis: a questionnaire study in Turkey. Am J Clin Dermatol. 2013;14(4):335-42.

29. Arsic Arsenijevic VS, Milobratovic D, Barac AM, Vekic B, Marinkovic J, Kostic VS. A laboratory-based study on patients with Parkinson's disease and seborrheic dermatitis: the presence and density of Malassezia yeasts, their different species and enzymes production. BMC Dermatol. 2014;14:5.

30. Ozkaya E. Adult-onset atopic dermatitis. J Am Acad Dermatol. 2005;52(4):579-82.

31. Aoyama H, Tanaka M, Hara M, Tabata N, Tagami H. Nummular eczema: an addition of senile xerosis and unique cutaneous reactivities to environmental aeroallergens. Dermatology. 1999;199(2):135-9.

32. Farage MA, Miller KW, Berardesca E, Maibach HI. Clinical implications of aging skin: cutaneous disorders in the elderly. Am J Clin Dermatol. 2009;10(2):73-86.

33. Schneider G, Driesch G, Heuft G, Evers S, Luger TA, Stander S. Psychosomatic cofactors and psychiatric comorbidity in patients with chronic itch. Clin Exp Dermatol. 2006;31(6):762-7.

34. Yosipovitch G, Tang MB. Practical management of psoriasis in the elderly: epidemiology, clinical aspects, quality of life, patient education and treatment options. Drugs Aging. 2002;19(11):847-63.

35. Henseler T, Christophers E. Psoriasis of early and late onset: characterization of two types of psoriasis vulgaris. J Am Acad Dermatol. 1985;13(3):450-6.

36. Lo Schiavo A, Ruocco E, Brancaccio G, Caccavale S, Ruocco V, Wolf R. Bullous pemphigoid: etiology, pathogenesis, and inducing factors: facts and controversies. Clin Dermatol. 2013;31(4):391-9.

37. Bastuji-Garin S, Joly P, Lemordant P, et al. Risk factors for bullous pemphigoid in the elderly: a prospective case-control study. J Invest Dermatol. 2011;131(3):637-43.

38. Hashimoto T, Kursewicz CD, Fayne RA, et al. Pathophysiological mechanisms of itch in bullous pemphigoid. J Am Acad Dermatol. 2019. https:// doi.org/10.1016/j.jaad.2019.07.060.
39. Yosipovitch G, Stander S, Kerby MB, et al. Serlopitant for the treatment of chronic pruritus: Results of a randomized, multicenter, placebo-controlled phase 2 clinical trial. J Am Acad Dermatol. 2018;78(5):882.

40. Cassell JA, Middleton J, Nalabanda A, et al. Scabies outbreaks in ten care homes for elderly people: a prospective study of clinical features, epidemiology, and treatment outcomes. Lancet Infect Dis. 2018;18(8):894-902.

41. Sanders KM, Nattkemper LA, Rosen JD, et al. Nonhistaminergic itch mediators elevated in the skin of a porcine model of scabies and of human scabies patients. J Invest Dermatol. 2019;139(4):971-3.

42. Rosen JD, Fostini AC, Yosipovitch G. Diagnosis and management of neuropathic itch. Dermatol Clin. 2018;36(3):213-24.

43. Yamaoka H, Sasaki H, Yamasaki H, et al. Truncal pruritus of unknown origin may be a symptom of diabetic polyneuropathy. Diabetes Care. 2010;33(1):150-5.

44. Yawn BP, Saddier P, Wollan PC, St Sauver JL, Kurland MJ, Sy LS. A population-based study of the incidence and complication rates of herpes zoster before zoster vaccine introduction. Mayo Clin Proc. 2007;82(11):1341-9.

45. Goodkin R, Wingard E, Bernhard JD. Brachioradial pruritus: cervical spine disease and neurogenic/ neuropathic [corrected] pruritus. J Am Acad Dermatol. 2003;48(4):521-4.

46. Marziniak M, Phan NQ, Raap U, et al. Brachioradial pruritus as a result of cervical spine pathology: the results of a magnetic resonance tomography study. J Am Acad Dermatol. 2011;65(4):756-62.

47. Kwatra SG, Stander S, Bernhard JD, Weisshaar E, Yosipovitch G. Brachioradial pruritus: a trigger for generalization of itch. J Am Acad Dermatol. 2013;68(5):870-3.

48. Pisoni RL, Wikstrom B, Elder SJ, et al. Pruritus in haemodialysis patients: international results from the Dialysis Outcomes and Practice Patterns Study (DOPPS). Nephrol Dial Transplant. 2006;21(12):3495-505.

49. Zucker I, Yosipovitch G, David M, Gafter U, Boner G. Prevalence and characterization of uremic pruritus in patients undergoing hemodialysis: uremic pruritus is still a major problem for patients with end-stage renal disease. J Am Acad Dermatol. 2003;49(5):842-6. 
50. Hashimoto T, Yosipovitch G. Itching as a systemic disease. $\mathrm{J}$ Allergy Clin Immunol. 2019;144(2):375-380.

51. Dull MM, Kremer AE. Management of chronic hepatic itch. Dermatol Clin. 2018;36(3):293-300.

52. Bergasa NV. Pruritus of Cholestasis. In: Carstens E, Akiyama T, editors. Itch: Mechanisms and treatment. Frontiers in neuroscience. Boca Raton: CRC; 2014.

53. Heitkemper T, Hofmann T, Phan NQ, Stander S. Aquagenic pruritus: associated diseases and clinical pruritus characteristics. J Dtsch Dermatol Ges. 2010;8(10):797-804.

54. Tefferi A, Rumi E, Finazzi G, et al. Survival and prognosis among 1545 patients with contemporary polycythemia vera: an international study. Leukemia. 2013;27(9):1874-81.

55. Hashimoto T, Rosen JD, Sanders KM, Yosipovitch G. Possible roles of basophils in chronic itch. Exp Dermatol. 2018. https://doi.org/10.1111/exd. 13705.

56. Gobbi PG, Attardo-Parrinello G, Lattanzio G, Rizzo SC, Ascari E. Severe pruritus should be a B-symptom in Hodgkin's disease. Cancer. 1983;51(10):1934-6.

57. Rowe B, Yosipovitch G. Paraneoplastic itch management. Curr Probl Dermatol. 2016;50:149-54.

58. Rubenstein M, Duvic M. Cutaneous manifestations of Hodgkin's disease. Int J Dermatol. 2006;45(3):251-6.

59. Vij A, Duvic M. Prevalence and severity of pruritus in cutaneous $\mathrm{T}$ cell lymphoma. Int $\mathrm{J}$ Dermatol. 2012;51(8):930-4.

60. Mills KC, Kwatra SG, Feneran AN, et al. Itch and pain in nonmelanoma skin cancer: pain as an important feature of cutaneous squamous cell carcinoma. Arch Dermatol. 2012;148(12):1422-3.

61. Yosipovitch G. Chronic pruritus: a paraneoplastic sign. Dermatol Ther. 2010;23(6):590-6.

62. Skoog I. Psychiatric disorders in the elderly. Can J Psychiatry. 2011;56(7):387-97.

63. Lee HG, Stull C, Yosipovitch G. Psychiatric disorders and pruritus. Clin Dermatol. 2017;35(3):273-80.

64. Shevchenko A, Valdes-Rodriguez R, Yosipovitch G. Causes, pathophysiology, and treatment of pruritus in the mature patient. Clin Dermatol. 2018;36(2):140-51.
65. Fowler E, Maderal A, Yosipovitch G. Treatment-induced delusions of infestation associated with increased brain dopamine levels. Acta Derm Venereol. 2019;99(3):327-8.

66. Steckelings UM, Artuc M, Wollschlager T, Wiehstutz S, Henz BM. Angiotensin-converting enzyme inhibitors as inducers of adverse cutaneous reactions. Acta Derm Venereol. 2001;81(5):321-5.

67. Reich A, Stander S, Szepietowski JC. Drug-induced pruritus: a review. Acta Derm Venereol. 2009;89(3):236-44.

68. Reich A, Szepietowski JC. Opioid-induced pruritus: an update. Clin Exp Dermatol. 2010;35(1):2-6.

69. Sibaud V. Dermatologic reactions to immune checkpoint inhibitors: skin toxicities and immunotherapy. Am J Clin Dermatol. 2018;19(3):345-61.

70. Fischer A, Rosen AC, Ensslin CJ, Wu S, Lacouture ME. Pruritus to anticancer agents targeting the EGFR, BRAF, and CTLA-4. Dermatol Ther. 2013;26(2):135-48.

71. Kalaaji AN, Wallo W. A randomized controlled clinical study to evaluate the effectiveness of an active moisturizing lotion with colloidal oatmeal skin protectant versus its vehicle for the relief of xerosis. J Drugs Dermatol. 2014;13(10):1265-8.

72. Pazyar N, Yaghoobi R, Kazerouni A, Feily A. Oatmeal in dermatology: a brief review. Indian J Dermatol Venereol Leprol. 2012;78(2):142-5.

73. Pan M, Heinecke G, Bernardo S, Tsui C, Levitt J. Urea: a comprehensive review of the clinical literature. Dermatol Online J. 2013;19(11):20392.

74. Young TA, Patel TS, Camacho F, et al. A pramoxinebased anti-itch lotion is more effective than a control lotion for the treatment of uremic pruritus in adult hemodialysis patients. J Dermatolog Treat. 2009;20(2):76-81.

75. Yosipovitch G, Samuel LS. Neuropathic and psychogenic itch. Dermatol Ther. 2008;21(1):32-41.

76. Andersen $\mathrm{HH}$, Arendt-Nielsen L, Elberling J. Topical capsaicin $8 \%$ for the treatment of neuropathic itch conditions. Clin Exp Dermatol. 2017;42(5):596-8.

77. Andersen HH, Sand C, Elberling J. Considerable variability in the efficacy of $8 \%$ capsaicin topical patches in the treatment of chronic pruritus in 3 patients with notalgia paresthetica. Ann Dermatol. 2016;28(1):86-9.

78. Laklouk M, Baranidharan G. Profile of the capsaicin $8 \%$ patch for the management of neuropathic pain 
associated with postherpetic neuralgia: safety, efficacy, and patient acceptability. Patient Prefer Adher. 2016;10:1913-8.

79. Zeidler C, Luling H, Dieckhofer A, et al. Capsaicin $8 \%$ cutaneous patch: a promising treatment for brachioradial pruritus? $\mathrm{Br} \mathrm{J}$ Dermatol. 2015;172(6):1669-71.

80. Lee HG, Grossman SK, Valdes-Rodriguez R, et al. Topical ketamine-amitriptyline-lidocaine for chronic pruritus: a retrospective study assessing efficacy and tolerability. J Am Acad Dermatol. 2017;76(4):760-1.

81. Poterucha TJ, Murphy SL, Davis MD, et al. Topical amitriptyline-ketamine for the treatment of brachioradial pruritus. JAMA Dermatol. 2013;149(2):148-50.

82. Eichenfield LF, Tom WL, Berger TG, et al. Guidelines of care for the management of atopic dermatitis: section 2. Management and treatment of atopic dermatitis with topical therapies. J Am Acad Dermatol. 2014;71(1):116-32.

83. Gupta AK, Versteeg SG. Topical treatment of facial seborrheic dermatitis: a systematic review. Am J Clin Dermatol. 2017;18(2):193-213.

84. Ropke MA, Alonso C, Jung S, et al. Effects of glucocorticoids on stratum corneum lipids and function in human skin-a detailed lipidomic analysis. J Dermatol Sci. 2017;88(3):330-8.

85. Stander S, Schurmeyer-Horst F, Luger TA, Weisshaar E. Treatment of pruritic diseases with topical calcineurin inhibitors. Ther Clin Risk Manag. 2006;2(2):213-8.

86. Gisondi P, Ellis CN, Girolomoni G. Pimecrolimus in dermatology: atopic dermatitis and beyond. Int J Clin Pract. 2005;59(8):969-74.

87. Kailas A. Crisaborole: a new and effective nonsteroidal topical drug for atopic dermatitis. Dermatol Ther. 2017;30(5):e12533.

88. Endo JO, Wong JW, Norman RA, Chang ALS. Geriatric dermatology: part I. Geriatric pharmacology for the dermatologist. J Am Acad Dermatol. 2013;68(4):521.

89. Trevor A, Katzung B, Kruidering-Hall M. Katzung and Trevor's pharmacology examination and board review. New York: McGraw Hill; 2013.

90. Hutchison L, Sleeper R, Asal N. Fundamentals of geriatric pharmacotherapy: an evidenced-based approach. Bethesda: ASHP; 2015.
91. American Geriatrics Society. Updated AGS Beers Criteria ${ }^{\circledR}$ for potentially inappropriate medication use in older adults. J Am Geriatr Soc. 2019;67(4):674-94.

92. Gray SL, Anderson ML, Dublin S, et al. Cumulative use of strong anticholinergics and incident dementia: a prospective cohort study. JAMA Intern Med. 2015;175(3):401-7.

93. Asero R, Tedeschi A, Cugno M. Treatment of chronic urticaria. Immunol Allergy Clin North Am. 2014;34(1):105-16.

94. Stander S, Bockenholt B, Schurmeyer-Horst F, et al. Treatment of chronic pruritus with the selective serotonin re-uptake inhibitors paroxetine and fluvoxamine: results of an open-labelled, two-arm proof-of-concept study. Acta Derm Venereol. 2009;89(1):45-51.

95. Mayo MJ, Handem I, Saldana S, Jacobe H, Getachew Y, Rush AJ. Sertraline as a first-line treatment for cholestatic pruritus. Hepatology. 2007;45(3):666-74.

96. Pongcharoen P, Fleischer AB Jr. An evidence-based review of systemic treatments for itch. Eur J Pain. 2016;20(1):24-31.

97. Torvinen-Kiiskinen S, Tolppanen AM, Koponen M, et al. Antidepressant use and risk of hip fractures among community-dwelling persons with and without Alzheimer's disease. Int J Geriatr Psychiatry. 2017;32(12):e107-15.

98. Hundley JL, Yosipovitch G. Mirtazapine for reducing nocturnal itch in patients with chronic pruritus: a pilot study. J Am Acad Dermatol. 2004;50(6):889-91.

99. Potts GA, Hurley MY. Psoriasis in the geriatric population. Clin Geriatr Med. 2013;29(2):373-95.

100. Gupta MA, Pur DR, Vujcic B, Gupta AK. Use of antiepileptic mood stabilizers in dermatology. Clin Dermatol. 2018;36(6):756-64.

101. Matsuda KM, Sharma D, Schonfeld AR, Kwatra SG. Gabapentin and pregabalin for the treatment of chronic pruritus. J Am Acad Dermatol. 2016;75(3):619.

102. Reszke R, Szepietowski JC. End-stage renal disease chronic itch and its management. Dermatol Clin. 2018;36(3):277-92.

103. Ganesh A, Maxwell LG. Pathophysiology and management of opioid-induced pruritus. Drugs. 2007;67(16):2323-33. 
104. Dawn AG, Yosipovitch G. Butorphanol for treatment of intractable pruritus. J Am Acad Dermatol. 2006;54(3):527-31.

105. Phan NQ, Bernhard JD, Luger TA, Stander S. Antipruritic treatment with systemic mu-opioid receptor antagonists: a review. J Am Acad Dermatol. 2010;63(4):680-8.

106. Fowler E, Yosipovitch G. Chronic itch management: therapies beyond those targeting the immune system. Ann Allergy Asthma Immunol. 2019. https://doi.org/10.1016/j.anai.2019.01.016.

107. Phan NQ, Lotts T, Antal A, Bernhard JD, Stander S. Systemic kappa opioid receptor agonists in the treatment of chronic pruritus: a literature review. Acta Derm Venereol. 2012;92(5):555-60.

108. Cowan A, Kehner GB, Inan S. Targeting itch with ligands selective for kappa opioid receptors. Handb Exp Pharmacol. 2015;226:291-314.

109. Mathur VS, Kumar J, Crawford PW, Hait H, Sciascia T. A multicenter, randomized, double-blind, placebo-controlled trial of nalbuphine ER tablets for uremic pruritus. Am J Nephrol. 2017;46(6):450-8.

110. Simpson EL, Akinlade B, Ardeleanu M. Two phase 3 trials of dupilumab versus placebo in atopic dermatitis. N Engl J Med. 2017;376(11):1090-1.

111. Blauvelt A, de Bruin-Weller M, Gooderham M, et al. Long-term management of moderate-to-severe atopic dermatitis with dupilumab and concomitant topical corticosteroids (LIBERTY AD CHRONOS): a 1-year, randomised, double-blinded, placebo-controlled, phase 3 trial. Lancet. 2017;389(10086):2287-303.

112. Ou Z, Chen C, Chen A, Yang Y, Zhou W. Adverse events of dupilumab in adults with moderate-tosevere atopic dermatitis: a meta-analysis. Int Immunopharmacol. 2018;54:303-10.

113. Erickson S, Nahmias Z, Rosman IS, Kim BS. Immunomodulating agents as antipruritics. Dermatol Clin. 2018;36(3):325-34.
114. Oetjen LK, Mack MR, Feng J, et al. Sensory neurons co-opt classical immune signaling pathways to mediate chronic itch. Cell. 2017;171(1):217.

115. McEwen MW, Fite EM, Yosipovitch G, Patel T. Drugs on the horizon for chronic pruritus. Dermatol Clin. 2018;36(3):335-44.

116. Stander S, Kwon P, Hirman J, et al. Serlopitant reduced pruritus in patients with prurigo nodularis in a phase 2, randomized, placebo-controlled trial. J Am Acad Dermatol. 2019;80(5):1395-402.

117. He A, Alhariri JM, Sweren RJ, Kwatra MM, Kwatra SG. Aprepitant for the treatment of chronic refractory pruritus. Biomed Res Int. 2017;2017:4790810.

118. Rivard J, Lim HW. Ultraviolet phototherapy for pruritus. Dermatol Ther. 2005;18(4):344-54.

119. Nakamura M, Koo JY. Phototherapy for the treatment of prurigo nodularis: a review. Dermatol Online J. 2016;22:13030.

120. Baldo A, Sammarco E, Plaitano R, Martinelli V, Monfrecola G. Narrowband (TL-01) ultraviolet B phototherapy for pruritus in polycythaemia vera. $\mathrm{Br}$ J Dermatol. 2002;147(5):979-81.

121. Bulur I, Erdogan HK, Aksu AE, Karapinar T, Saracoglu ZN. The efficacy and safety of phototherapy in geriatric patients: a retrospective study. An Bras Dermatol. 2018;93(1):33-8.

122. Legat FJ. Is there still a role for UV therapy in itch treatment?. Exp Dermatol. 2019. https://doi.org/10. 1111/exd.14011.

123. Powell JB, Gach JE. Phototherapy in the elderly. Clin Exp Dermatol. 2015;40(6):605-10.

124. Gloor M, Scherotzke A. Age dependence of ultraviolet light-induced erythema following narrow-band UVB exposure. Photodermatol Photoimmunol Photomed. 2002;18(3):121-6. 